\title{
Safer dispensing labels for prescription medicines
}

\section{Adam La Caze \\ Lecturer \\ School of Pharmacy \\ Pharmacy Australia Centre \\ of Excellence \\ University of Queensland}

\section{Keywords}

medication adherence, medication errors, product labelling

Aust Prescr 2018;41:46-9

https://doi.org/10.18733/ austprescr.2018.009

\section{SUMMARY}

The standard way in which directions are represented on dispensing labels can be misinterpreted.

Errors in interpreting instructions are more common in people with low health literacy and when the timing of administration is not specified.

Improving written communication on prescriptions and dispensing labels can reduce medication errors.

There is an emerging international consensus on best-practice communication on dispensing labels.

\section{Introduction}

Dispensing labels on prescribed medicines provide administration instructions and important warnings. These remain with the consumer after the initial consultation when some of the confusion and worry frequently associated with illness has started to recede. Incorrect information on a label can have disastrous consequences,' but even correct information can contribute to medication errors.

An Australian Prescriber report described three cases of paediatric dosing errors involving prednisolone. ${ }^{2}$ In each case, parents administered prednisolone three times a day rather than daily as intended. While the directions on the label appeared to be correct - for example 'give $3 \mathrm{~mL}$ daily after food for three days' - they were misinterpreted. Research has found these types of errors are relatively common and can be reduced by better communication on dispensing labels. ${ }^{3,4}$

\section{Health literacy}

Health literacy refers to the ability of individuals to access, understand and use information to maintain good health. There are two components to health literacy - individual health literacy and the health literacy environment. Individual health literacy refers to an individual's skills, knowledge and capacity to access, understand and act on health information, and the health literacy environment refers to the ways in which the health system affects the ability of someone to access, understand and use information to maintain their health. ${ }^{5}$ Improving the written communication on dispensing labels is a good example of how improving the health literacy environment can improve patient care.

\section{Medication errors}

In a US trial, 395 participants were given five common prescription medicines with a dispensing label and asked how they would take the medicine. ${ }^{4}$ The medicines and their instructions included:

- amoxicillin, 'take one teaspoonful by mouth three times a day'

- furosemide (frusemide), 'take one tablet in the morning and one at $5 \mathrm{pm}$ '

- guaifenesin, 'take two tablets by mouth twice daily'.

Almost half of the participants misunderstood one or more of the dispensing labels. Errors were more common in those with low health literacy (reading ability of sixth grade or less) and when less explicit directions were provided. For instance, $41.3 \%$ of participants with low health literacy misunderstood the directions for amoxicillin, whereas only $17.3 \%$ of the participants with low health literacy misunderstood the more explicit directions for furosemide (frusemide). A separate analysis of the same study showed that errors in relation to the amoxicillin directions were a mixture of misunderstanding the measurement of the dose and the timing of administration. For example 'take one teaspoonful by mouth three times a day' was misunderstood as 'take three teaspoons daily' or 'take three tablespoons every day' ${ }^{6}$

Having someone accurately describe the dose of a medicine does not mean that they will take the correct dose. Participants were asked how many guaifenesin tablets they would take each day when instructed to 'take two tablets by mouth twice daily'. ${ }^{4}$ Some participants who could appropriately describe the recommended dose still made an error when asked to demonstrate how many tablets they would 
take in a day. This occurred in people with both high and low health literacy. However, in those with high health literacy, $89.4 \%$ correctly described the dose and $80.2 \%$ correctly demonstrated the number of tablets to be taken daily. For participants with low health literacy, $70.7 \%$ correctly described the dose but only $34.7 \%$ correctly demonstrated the daily dose.

In the same trial, participants interpreted 'take two tablets by mouth twice daily' in a variety of ways. ${ }^{6}$ Interpretations included 'take one tablet every 8 hours', 'take one tablet every 12 hours' and 'take tablets every day'. Adding details about the duration of treatment led to further variation in how people interpreted directions. Some participants omitted information about duration from their understanding of the directions, others mentioned duration at the expense of information regarding the number of tablets or interval. For instance, some people interpreted 'take two tablets twice a day for 7 days' as 'take it for 7 days' or 'take one every day for a week'.

These findings provided an impetus for re-thinking how information is communicated on dispensing labels.

\section{Patient-centred labels}

There is an emerging consensus for communicating less confusing, more informative and safer information on dispensing labels. ${ }^{7-9}$ These labels have been called patient-centred labels, and recommendations have been developed based on research in health literacy and health communication (see Box 1). 3,10,11 Advice includes:

- $\quad$ use larger font sizes (e.g. 12 point and above)

- present complex information in lists rather than paragraphs when possible

- use numbers rather than words to convey numeric information, for example 'take 2 tablets...' rather than 'take TWO tablets...'

- provide explicit dosing instructions, for example 'take 2 tablets in the morning, and take 2 tablets in the evening' rather than 'take TWO tablets TWICE a day'

- use white space and typographical cues (e.g. capitals) to communicate important information

- use standard dosing times for medicine administration, for example 'morning, noon, evening, bedtime' rather than 'TWICE daily', 'FOUR times daily' or 'every SIX hours'

- include the indication for the medicine when possible.

The use of standard dosing times, 'morning, noon, evening, bedtime', has been labelled the 'universal medication schedule'. 10,12 The use of standard dosing times is feasible for most drugs and is less confusing, more informative and makes it easier for patients to consolidate multiple medicines into fewer dosing times throughout the day. ${ }^{4,9}$

\section{How effective are patient-centred dispensing labels?}

A number of studies have assessed patientcentred labels. ${ }^{12-14}$ One trial randomised 845 participants to receive a patient-centred label or standard dispensing label for their medicine. ${ }^{12}$ The study assessed whether participants could show appropriate use of the medicine at baseline, three months and nine months. 'Appropriate use' meant the participant could report how many tablets or capsules per dose, how many times the medicine needed to be taken per day, and the total number of tablets or capsules to be taken per day. Those who received patient-centred labels were better at describing their medicine use at baseline (nominally) and at nine months compared with those who received standard dispensing labels ( $76.9 \%$ vs $70.1 \%, p=0.06$ at baseline, $85.9 \%$ vs $77.4 \%, p=0.03$ at 9 months). There was no difference between the groups at three months.

This study included participants who were fluent in either English or Spanish. Spanish-speaking participants did not receive the same benefit from patient-centred labels that was observed in English-speaking participants. ${ }^{12}$ This finding highlights the importance of further research in the use of patient-centred labels in patients from non-English speaking backgrounds. Most of the studies to date have excluded people who do not speak English.

\section{Box 1 Proposed standards for patient-centred labels}




\section{Medication adherence}

The study comparing patient-centred labels with standard dispensing labels also assessed medication adherence. ${ }^{12}$ While there was no difference in adherence in the groups overall, participants with low health literacy who received patient-centred labels were more likely to adhere to their medicine than those who received standard labels.

\section{The Australian context}

Almost $60 \%$ of Australian adults have low health literacy. ${ }^{5}$ It is easy for health professionals to underestimate the workload expected of consumers in managing their care and the care of family members. ${ }^{15,16}$ Patient-centred labels improve the healthcare environment by helping people to manage their medicines. They are an important addition to the face-to-face communication that occurs in consultations between the consumer and prescribers, pharmacists and other health professionals.

\section{Guidelines}

The specific legislative requirements for dispensing labels provided by pharmacists, prescribers, nurse practitioners and dentists are defined in statebased regulations and are informed by the Poisons Standard. ${ }^{17}$ The Pharmacy Board of Australia's Guidelines for Dispensing of Medicines provides best-practice guidance for the labelling of dispensed medicines (this guidance does not currently include specific recommendations for patient-centred labels). ${ }^{18}$ Box 2 provides Pharmacy Board of Australia guidance regarding the content that should be included on the label of a dispensed medicine. ${ }^{18}$
Box 1 provides guidance for patient-centred labels developed by the US Institute of Medicine. ${ }^{10}$ Similar guidance has been issued locally and internationally. ${ }^{7-9}$ The Australian Commission on Safety and Quality in Health Care is currently developing national standards for pharmacy dispensing labels. National standards are essential to guide practice and inform collaborative efforts to improve communication on dispensing labels. Challenges include deciding how best to implement the recommendations in Australia as labelling practices differ internationally and key studies have implemented patient-centred labels in slightly different ways. Also, making the necessary changes to prescribing and dispensing software and associated support systems will be a major undertaking, and further research is needed to ensure the effectiveness of patient-centred labels for people from non-English speaking backgrounds.

It is also possible that label dimensions need review. Currently it is difficult to present even relatively simple directions in a sufficient font size with surrounding white space to aid readability. The Table provides examples of common instructions provided in a way that implements the recommendations for patient-centred labels..$^{12-14,19}$

While there is work to be done to ensure patient-centred labels are implemented in Australia in a safe and effective manner, some aspects can be implemented immediately. Prescribers should, when possible, avoid 'as directed' and provide the indication. They should also give dosing directions at standard dosing times. If possible, pharmacists should provide explicit directions using standard dosing times, align warning labels horizontally, and discuss the inclusion of the indication on the dispensing label with the consumer.

\section{Box 2 What should be included in a medicine label?}

Brand and generic names of the medicine, and the strength, dose form and quantity supplied

Specific directions for use, including frequency and dose Patient's name

Date of dispensing or supply

Initials of the dispensing pharmacist (and if different, the initials of the pharmacist checking and issuing the medicine)

Name, address and telephone number of the dispensing pharmacy

Storage directions and expiry date of the medicine

The words 'Keep out of reach of children'

Based on the Pharmacy Board of Australia's Guidelines for Dispensing of Medicines. Refer to the Guidelines for the Board's full list. ${ }^{18}$

\section{Table Examples of instructions on medicine labels}

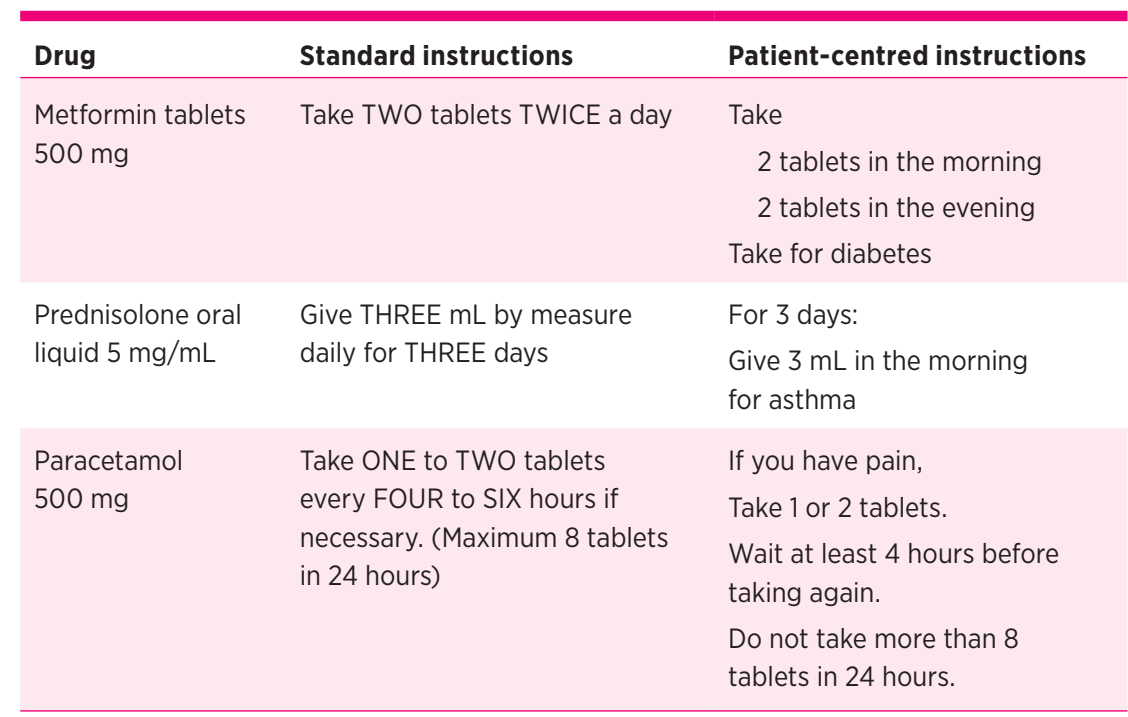

Source: References 12-14, 19 


\section{Conclusion}

What is considered best practice for dispensing labels is changing. Implementing these recommendations will require changes in prescribing and pharmacy practice and their support systems. Improving communication on dispensing labels helps consumers to safely manage their medicines and is an important addition to specific verbal advice on medication use. $\varangle$

\section{Conflict of interest: none declared}

\section{REFERENCES}

1. Institute for Safe Medication Practices. Severe harm and death associated with errors and drug interactions involving low-dose methotrexate [Internet]. Acute Care ISMP Medication Safety Alert 8 October 2015. www.ismp.org/ newsletters/acutecare/showarticle.aspx?id=121 [cited 2018 Mar 1]

2. Robinson J, McKenzie C, MacLeod D. Paediatric dosing errors with oral prednisolone mixture. Aust Prescr 2016;39:176. https://doi.org/10.18773/austprescr.2016.062

3. Shrank W, Avorn J, Rolon C, Shekelle P. Effect of content and format of prescription drug labels on readability, understanding, and medication use: a systematic review. Ann Pharmacother 2007;41:783-801. https://doi.org/10.1345/ aph.1H582

4. Davis TC, Wolf MS, Bass PF 3rd, Thompson JA, Tilson $\mathrm{HH}$, Neuberger $M$, et al. Literacy and misunderstanding prescription drug labels. Ann Intern Med 2006;145:887-94. https://doi.org/10.7326/0003-4819-145-12-200612190-00144

5. Australian Bureau of Statistics. 4233.0 - Health literacy, Australia, 2006. Canberra: Australian Bureau of Statistics; 2008. http://www.abs.gov.au/AUSSTATS/abs@.nsf/ DetailsPage/4233.02006? OpenDocument [cited 2018 Mar 1]

6. Wolf MS, Davis TC, Shrank W, Rapp DN, Bass PF, Connor UM, et al. To err is human: patient misinterpretations of prescription drug label instructions. Patient Educ Couns 2007;67:293-300. https://doi.org/10.1016/j.pec.2007.03.024

7. International Medication Safety Network. IMSN position paper on making medicines naming, labelling and packaging safer [Internet]. October 2013. https://www.intmedsafe.net/ imsn-advocacy/imsn-papers/safer-packaging-and-labelling [cited 2018 Mar 1]

8. Australian Commission on Safety Quality in Health Care, NSW Clinical Excellence Commission. Improving the safety and quality of pharmacy dispensing labels. National round table report 25 November 2013. Sydney: ACSQHC; 2014. https://www.safetyandquality.gov.au/wp-content/ uploads/2013/11/Pharmacy-Dispensing-Label-Workshop-25Nov-2013-report-.pdf [cited 2018 Mar 1]

9. Institute for Safe Medication Practices. Principles of designing a medication label for community and mail order pharmacy prescription packages [Internet]. 2010. www.ismp.org/tools/guidelines/labelFormats/comments/ default.asp [cited 2018 Mar 1]
10. Institute of Medicine. Standardizing medication labels: confusing patients less, workshop summary [Internet] Washington, DC: The National Academies Press; 2008. www.nap.edu/catalog/12077/standardizing-medicationlabels-confusing-patients-less-workshop-summary [cited 2018 Mar 1]

11. Sansom L, editor. Australian pharmaceutical formulary and handbook: the everyday guide to pharmacy practice. 23rd ed. Canberra: Pharmaceutical Society of Australia; 2015.

12. Wolf MS, Davis TC, Curtis LM, Bailey SC, Knox JP, Bergeron A, et al. A patient-centered prescription drug label to promote appropriate medication use and adherence. J Gen Intern Med 2016;31:1482-9. https://doi.org/10.1007/ s11606-016-3816-x

13. Sahm LJ, Wolf MS, Curtis LM, Behan R, Brennan M, Gallwey $\mathrm{H}$, et al. What's in a label? An exploratory study of patient-centered drug instructions. Eur J Clin Pharmacol 2012;68:777-82. https://doi.org/10.1007/s00228-011-1169-2

14. Bailey SC, Sarkar U, Chen AH, Schillinger D, Wolf MS. Evaluation of language concordant, patient-centered drug label instructions. J Gen Intern Med 2012;27:1707-13. https://doi.org/10.1007/s11606-012-2035-3

15. May C, Montori VM, Mair FS. We need minimally disruptive medicine. BMJ 2009;339:b2803. https://doi.org/10.1136/ bmj.b2803

16. Montori VM. Treat the numbers or treat the patient? Aust Prescr 2011;34:94-5. https://doi.org/10.18773/ austprescr.2011.054

17. Therapeutic Goods Administration. Poisons Standard June 2017 [Internet]. www.legislation.gov.au/Details/ F2017L00605/Html/Text\#_Toc471222279 [cited 2018 Mar 1].

18. Pharmacy Board of Australia. Guidelines for dispensing of medicines [Internet]. September 2015. www.pharmacyboard.gov.au/Codes-Guidelines.aspx [cited 2018 Mar 1]

19. Shrank WH, Parker R, Davis T, Pandit AU, Knox JP, Moraras P, et al. Rationale and design of a randomized trial to evaluate an evidence-based prescription drug label on actual medication use. Contemp Clin Trials 2010;31:564-71. https://doi.org/10.1016/j.cct.2010.07.004 